\title{
Characterisation of Culex quinquefasciatus (Diptera: Culicidae) larval habitats at ground level and temporal fluctuations of larval abundance in Córdoba, Argentina
}

\author{
Marta Grech/ ${ }^{+}$, Paolo Sartor, Elizabet Estallo, Francisco Ludueña-Almeida, Walter Almirón \\ Centro de Investigaciones Entomológicas de Córdoba, Instituto de Investigaciones Biológicas y Tecnológicas, \\ Consejo Nacional de Investigaciones Científicas y Técnicas, Universidad Nacional de Córdoba, Córdoba, Argentina
}

The aims of this study were to characterise the ground-level larval habitats of the mosquito Culex quinquefasciatus, to determine the relationships between habitat characteristics and larval abundance and to examine seasonal larval-stage variations in Córdoba city. Every two weeks for two years, 15 larval habitats (natural and artificial water bodies, including shallow wells, drains, retention ponds, canals and ditches) were visited and sampled for larval mosquitoes. Data regarding the water depth, temperature and $\mathrm{pH}$, permanence, the presence of aquatic vegetation and the density of collected mosquito larvae were recorded. Data on the average air temperatures and accumulated precipitation during the 15 days prior to each sampling date were also obtained. $\mathrm{Cx}$. quinquefasciatus larvae were collected throughout the study period and were generally most abundant in the summer season. Generalised linear mixed models indicated the average air temperature and presence of dicotyledonous aquatic vegetation as variables that served as important predictors of larval densities. Additionally, permanent breeding sites supported high larval densities. In Córdoba city and possibly in other highly populated cities at the same latitude with the same environmental conditions, control programs should focus on permanent larval habitats with aquatic vegetation during the early spring, when the $\mathrm{Cx}$. quinquefasciatus population begins to increase.

Key words: Culex quinquefasciatus - mosquito larval habitats - statistical model - Argentina

Mosquitoes affect humans and animals by transmitting the disease-causing agents of several serious diseases. Such arboviral diseases likely represent the major threat to public health in Argentina, where the St. Louis encephalitis (SLEV) flavivirus has been isolated from Culex quinquefasciatus mosquitoes collected in central regions (Díaz et al. 2006). In 2005, the largest SLEV epidemic in South America and Argentina occurred in Córdoba Province, resulting in at least 47 human cases and nine deaths (Almirón et al. 2006, Spinsanti et al. 2008). In 2010, 43 cases of SLEV were identified in Argentina, four of which were reported in Córdoba Province (OPS 2010).

The successful application of integrated mosquito control techniques requires an adequate understanding of mosquito larval habitats as well as the features of temporal dynamics. The number of studies addressing natural and artificial mosquito larval habitats has increased in recent years in the central (Almirón \& Brewer 1996, Fischer et al. 2000, Fischer \& Schweig-

\footnotetext{
doi: 10.1590/0074-0276108062013014

Financial support: CONICET, SECYT-UNC

WA is a scientific member of CONICET, Argentina, MG is scholarship holders of CONICET, Argentina.

+Corresponding author: grechmarta@gmail.com

Received 6 July 2012

Accepted 22 May 2013
}

mann 2004, 2010, Pires \& Gleiser 2010) and northeastern regions of Argentina (Stein et al. 2002a, b, 2005, 2011). Cx. quinquefasciatus can use containers as larval habitats and shows the ecological plasticity to breed in both polluted and clear waters (Forattini 2002). Almirón and Brewer (1996) described and classified immaturestage mosquito habitats in Córdoba Province, where $C x$. quinquefasciatus was grouped together with other Culex species that shared the same habitat requirements, with Cx. quinquefasciatus being found to be more frequent in artificial larval habitats. In another study, artificial and natural larval habitats (pools, ditches, canals, lagoons and water sources) were surveyed in Córdoba city during the summer months. Several species of Aedes, Culex and Mansonia were identified and $C x$. quinquefasciatus was shown to be the most abundant and most widely distributed in the city (Pires \& Gleiser 2010). Furthermore, the temporal dynamics of $C x$. quinquefasciatus populations have been investigated in Buenos Aires (Fischer et al. 2000, Fischer \& Schweigmann 2010) and Córdoba (Almirón \& Brewer 1995), where this mosquito species was reported to be present throughout the year.

Knowledge of mosquito larval habitats is essential for identifying the most productive sites in a given area and developing effective control methods. This study attempted to determine which ecological factors related to larval habitat dynamics drive $C x$. quinquefasciatus abundance. The aim of this study was to characterise the ground-level mosquito larval habitats of $C x$. quinquefasciatus, to determine the relationships between habitat characteristics and larval abundance and to study seasonal larval-stage variations in Córdoba city. 


\section{MATERIALS AND METHODS}

Study area - The study was conducted in Córdoba city $\left(31^{\circ} 22^{\prime} \mathrm{S} 64^{\circ} 12^{\prime} \mathrm{W}\right)$, which is located at $360-480 \mathrm{~m}$ above sea level. Córdoba city is the main city and capital of Córdoba Province (Argentina) and has a resident human population of 1,330,023 inhabitants (INDEC 2010). Córdoba city covers a land area of $576 \mathrm{Km}^{2}$ and approximately $37.2 \%$ of the city surface is urbanised, which is surrounded by agricultural fields (Jarsún et al. 2003). The climate is temperate with distinctively hotter-wet (October-April mean maximum and minimum temperatures: $27.15^{\circ} \mathrm{C}$ and $14.87^{\circ} \mathrm{C}$, respectively; mean monthly rainfall: $111.43 \mathrm{~mm}$ ) and cooler-dry (May-September mean maximum and minimum temperatures: $19.66^{\circ}$ and $6.1^{\circ} \mathrm{C}$, respectively; mean monthly rainfall: $17.98 \mathrm{~mm}$ ) seasons (SMN 2011).

Mosquito sampling - Córdoba city was partitioned into 100 plots of $4 \mathrm{~km}^{2}$ each, 52 of which were located in the urbanised area. These 52 plots were numbered and represented potential sampling positions. Fifteen plots were randomly selected in the urban public area. In each selected plot, preliminary samplings were performed to detect the mosquito larval habitats of $C x$. quinquefasciatus at ground level (natural and artificial water bodies, including shallow wells, drains, retention ponds, canals and ditches). Sampling plots near downtown were discarded because of the difficulty of finding these types of mosquito larval habitats and were replaced successively by other nearby plots to set up the scheme shown in Fig. 1. Once detected, only one larval habitat within each plot was selected. Field sites were sampled for larval mosquitoes every two weeks from June 2008-June 2010 (Fig. 1). Three samples were collected from each larval habitat using a standard white $350-\mathrm{mL}$ dipper. The collected material was transferred to the laboratory in small plastic flasks. The third and fourth-instar larvae were killed and stored in $80 \%$ ethanol for taxonomic determination according to available keys (Darsie 1985). The younger (1st and 2nd) instars were reared incubated until reaching the fourth instar in plastic trays with $750 \mathrm{~mL}$ of water from a natural larval habitat and were fed $0.25 \mathrm{mg}$ of liver powder per larva daily. The water surface was cleaned each day with filter paper to avoid complications due to fungal and bacterial development.

For each larval habitat and sampling date, the following characteristics were recorded: water depth (WD), temperature and $\mathrm{pH}$, permanence, the presence of aquatic vegetation and the number of mosquito larvae collected. Density was expressed as the number of larvae per dip (total number of larvae/number of dips). The average WD was estimated from three measurements performed at random along the edges and in the middle of the larval habitat. Water temperature (WT) and $\mathrm{pH}$ were determined in the field with a digital thermo-pH-meter. Because the larval habitats were systematically sampled (the route, which included the selected larval habitats, began at the laboratory starting point at 08:00 am, ran through sites 1-15 and reached the laboratory end point at approximately 12:30 am, covering approximately 80 $\mathrm{km}$ ), the WT measurements were corrected to compare the obtained datasets using the following formula:

$$
T C_{i, t}=\overline{T O}_{t}+T O_{i, t}-T P_{i, t}
$$

where $T C_{i, t}$ is the corrected WT from larval habitat $i$, registered on date $t, \overline{T O}_{t}$ is the average WT of the 15 larval habitats on date $t, T O_{i, t}$ is the WT from larval habitat $i$, measured in the field on date $t$, and $T P_{i, t}$ is the predicted WT for larval habitat $i$ on date $t$, calculated for each sampling date via linear regression between $T O_{i}$ vs. the time of day $(h)$ at which it was registered. Then, $T P_{i}(h)=a+$ $b h$ where $T P_{i}(h)$ is the predicted WT from larval habitat $i$ and $h$ is the time of day. The presence or absence $(1 / 0)$ of aquatic emergent vegetation was recorded and the plants were broadly grouped into monocotyledons and dicotyledons. Water permanence was recorded as the percentage of sampling dates on which each larval habitat contained water. The daily air temperature and precipitation data for Córdoba city were provided by the National Meteorological Service. The average mean daily air temperature and accumulated precipitation for the 15 days prior to each sampling date were calculated.

Data analysis - Data from the examined two-year period were analysed with a paired $t$ test to compare the larval abundances pooled by date (paired between years). To evaluate the relationship between the observed $C x$. quinquefasciatus larval density, habitat characteristics and meteorological variables, we used generalised linear mixed models (GLMMs) with a negative binomial family distribution and logarithmic link function (Crawley 2007, Zuur et al. 2009). The application of GLMM techniques allows ecologists to address elements such as nested data, temporal and spatial correlations, data with many zeros and heterogeneity of variance. Furthermore, negative binomial GLMMs are useful for modelling ecological datasets that show overdispersion, in which the variance is larger than the mean (Zuur et al. 2009). Such models are referred to as mixed because they include both fixed and random components. The fixed components are defined as the factors for which the levels are experimentally determined or the interest lies in the specific effects of each level, such as the effects of covariates or differences among treatments and interactions, while the random components are defined as the factors for which the levels are sampled from a larger population or the interest lies in the variation among them rather than the specific effects of each level. In the present study, we applied a random intercept model wherein the intercept was allowed to change for each site. The WT, temperature and $\mathrm{pH}$, presence of aquatic vegetation (monocotyledons and dicotyledons), average air temperature and accumulated precipitation 15 days prior to each sampling date were included as fixed effects. The larval habitat was included as a random effect. We chose the larval habitat as a random effect of the mixed model to account for the lack of independence or pseudoreplication associated with the collection of multiple measurements and samples from the same sites over time. Additionally, we were not interested in determining the exact nature of the site effect. We employed a backward selection procedure in which we removed non-significant terms from the model, one by one, in decreasing order of their p-values (Crawley 2007). Statistical analyses were performed with R software, ver- 
sion 2.15.1 (glmmADMB package) (R Core Team 2012). To apply the mixed effects model (MEM) in R, we used the following code:

$>$ library $($ glmmADMB) $>$ MEM $<$ glmmadmb $($ datos $\$ D L$ $\sim \mathrm{T} 15+\mathrm{P} 15+\mathrm{pH}+\mathrm{WT}+\mathrm{WD}+\mathrm{VAm}+\mathrm{VAd}+(1 \mid$ Site $)$, zeroInflation $=$ FALSE, data $=$ datos, family $=$ "nbinom") $>$ summary(MEM)

where the MEM was applied using the glmmadmb function. The response variable DL represents the larval density of $C x$. quinquefasciatus. The included fixed effects were the averaged air temperature $\left(T_{15}\right)$ and accumulated precipitation $\left(P_{15}\right)$ on the 15 days prior to the sampling date as well as the $\mathrm{pH}, \mathrm{WT}$, WD and monocotyledonous and dicotyledonous aquatic emergent vegetation (VAm, VAd). The random term 1|Site specifies a random intercept model. The argument on the right hand side of the $\mid$ symbol is a nominal variable (site). The summary command provides the output of the model.

\section{RESULTS}

Characterisation of larval habitats - Six species belonging to two genera were identified in the mosquito larval habitats. Cx. quinquefasciatus represented 99.64\% of the total, while Culex bidens-mollis, Culex apicinus, Culex eduardoi-dolosus, Culex saltanensis and Ochlerotatus albifasciatus represented $0.17 \%, 0.16 \%, 0.007 \%$, $0.005 \%$ and $0.02 \%$ of the collected species, respectively. The average number of $C x$. quinquefasciatus larvae obtained per dip varied from 0.04-263.6. The mean water
$\mathrm{pH}$ ranged from 5.59-6.46, the WT from $14.95-22.2^{\circ} \mathrm{C}$, the WD from $7.08-28.92 \mathrm{~cm}$ and permanence from $41-$ 100\% (Table I).

Temporal variations in $C x$. quinquefasciatus larval abundance - Cx. quinquefasciatus larvae were collected throughout the entire study period. The total number of larvae collected during the first season (59,410 larvae) was significantly greater $(\mathrm{t}=2.66 ; \mathrm{p}=0.0151)$ than that in the second season (20.493 larvae). The initially recorded presence of immature stages gradually decreased during the winter period (June-September) in both seasons. However, in early September 2008-2009 and October 20092010, the density of $C x$. quinquefasciatus larvae increased markedly. The highest larval density peak was recorded in February 2009 and another, less important, peak was observed at the end of March 2009. No considerable increases were detected during the second season (Fig. 2B).

The mean air temperature and accumulated precipitation recorded during the first season were $19.53^{\circ} \mathrm{C}$ and $563.4 \mathrm{~mm}$, respectively. During the second study period, the mean temperature was $18.61^{\circ} \mathrm{C}$ and the accumulated precipitation was $1,085.2 \mathrm{~mm}$. The average air temperatures and accumulated precipitation observed in the 15 days prior to the sampling dates for the entire study period are included in Fig. 2A.

Habitat characteristics and meteorological variables in relation to $C x$. quinquefasciatus larval abundance The variables from the GLMM that best described the relationship between the $C x$. quinquefasciatus larval

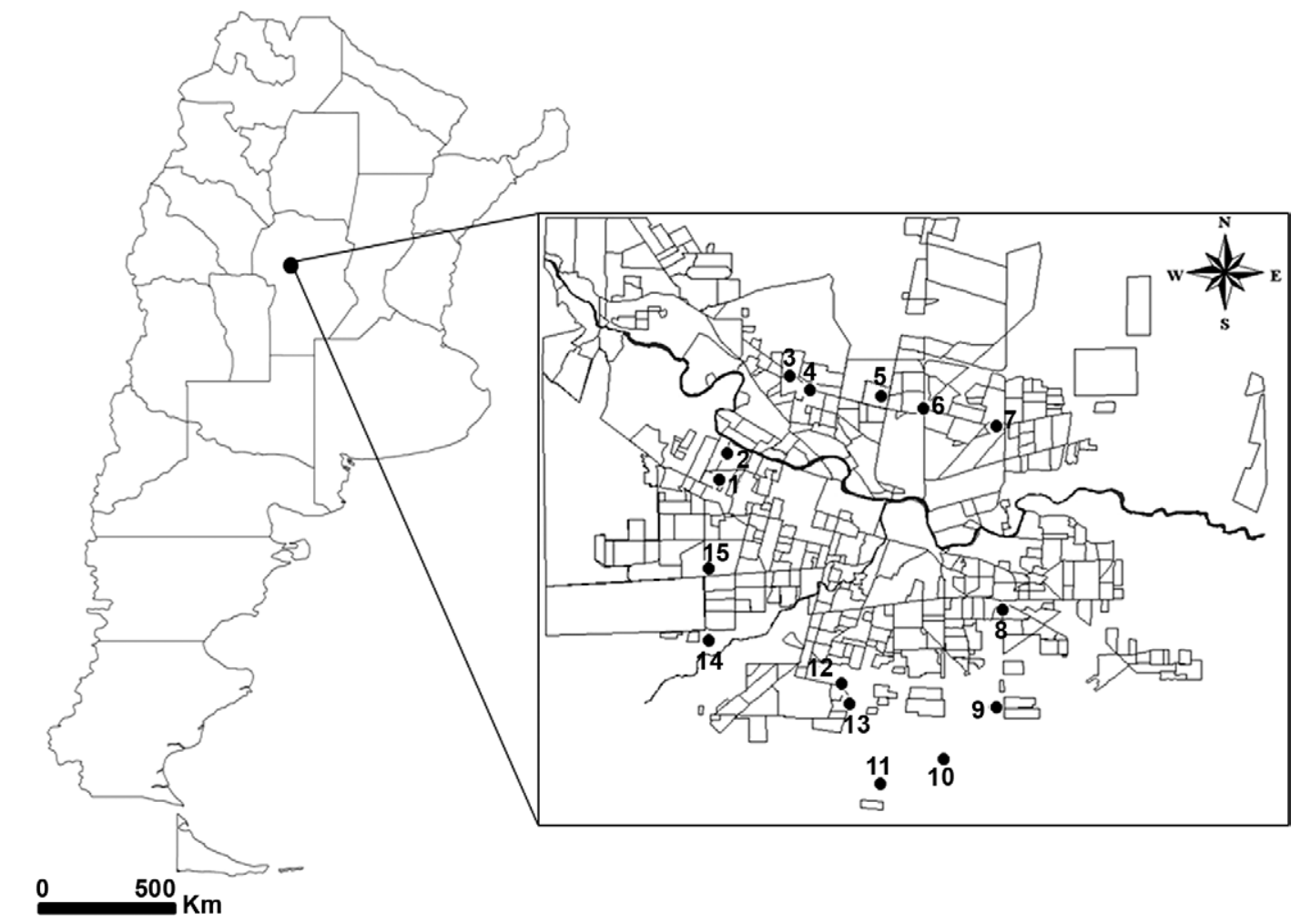

Fig. 1: map of Argentina. Location of 15 sampled larval habitats in Córdoba city (Córdoba Province), Argentina. 
density and the examined habitat characteristics and meteorological variables were the average air temperature during the 15 days prior to the sampling date $(\mathrm{z}=2.54$; $p=0.011)$ and the presence of dicotyledonous aquatic emergent vegetation $(z=2.47 ; p=0.014)$. The other explanatory variables were not significantly related to the larval density $(\mathrm{p}>0.05)$ (Table II).

\section{DISCUSSION}

In the present study, the average air temperature two weeks prior to each sampling date was found to be an important predictor of the Cx. quinquefasciatus larval density. However, the accumulated precipitation was not related to this variable, which could be due to the fact that almost all of the studied larval habitats with high larval densities were permanent and their water sources were mainly sewage and irrigation water, rather than rainfall. Relationships between larval abundances and meteorological variables have also been reported by other authors, though with differing results being obtained. Almirón and Brewer (1995) observed that in artificial larval habitats in Córdoba city, which were mainly rainfilled, the larval abundance of $C x$. quinquefasciatus was not correlated with variables such as air temperature and rainfall. However, in Buenos Aires city, the larval abundance of Culex pipiens was found to be positively associated with the mean weekly air temperature (Fischer et al. 2000, Fischer \& Schweigmann 2004).

The presence of dicotyledonous aquatic emergent vegetation was also an important predictor of larval density in this study. Aquatic vegetation provides protection from predators and physical disturbances such as wind action and increases the availability of food, thus offering a more suitable habitat for immature mosquitoes (Russell 1999). Relationships between vegetation and larval abundance have been previously reported in Córdoba Province, where 42 localities were sampled to describe and classify mosquito larval habitats and the presence of aquatic vegetation in $C x$. quinquefasciatus larval habitats was indicated as the most important feature related to the larval abundance of this species (Almirón \& Brewer 1996). Pires and Gleiser (2010) observed that, in natural and artificial larval habitats in Córdoba city, medium and high larval densities occurred in ditches and canals and were associated with the presence of vegetation. Positive associations between increasing vegetation cover and immature $C x$. quinquefasciatus abundance have also been reported in the Buenos Aires (Fischer \& Schweigmann 2004) and Chaco Provinces (Stein et al. 2002a, 2005, 2011).

Mosquito populations are sensitively dependent on the WTs in their larval habitats, which can directly affect larval survival and development times and indirectly increase decomposition processes and food availability (Clements 1992, Lindblade et al. 2000). In the present study, WT could not explain the observed variation in $C x$. quinquefasciatus larval densities. However, the lack of an association between these variables does not represent sufficient evidence to conclude that the WT is less important in explaining larval density. The measurements of this variable conducted during our research only reflect the WT at a single point for each larval habitat and sampling date, rather than variations that would influence larval abundances.

The mean $\mathrm{pH}$ values observed in this study were always within the acidic $\mathrm{pH}$ range (range: 5.59-6.46) and were not related to the $C x$. quinquefasciatus larval den-

TABLE I

Mean larval density (DL) \pm standard deviation (SD) of Culex quinquefasciatus collected at 15 larval habitats and mean values of $\mathrm{pH}$, water temperature (WT) and water depth (WD) registered in each site

\begin{tabular}{|c|c|c|c|c|c|c|c|}
\hline Site $^{a}$ & $\begin{array}{c}\text { Type of } \\
\text { larval habitat }\end{array}$ & $\mathrm{DL} \pm \mathrm{SD}$ & $\begin{array}{c}\text { Permanence }^{b} \\
(\%)\end{array}$ & $\begin{array}{c}\text { Aquatic } \\
\text { vegetation }\end{array}$ & $\mathrm{pH}$ & $\begin{array}{l}\text { WT } \\
\left({ }^{\circ} \mathrm{C}\right)\end{array}$ & $\begin{array}{l}\text { WD } \\
(\mathrm{cm})\end{array}$ \\
\hline 2 & DR & $263.6 \pm 346.12$ & 100 & VAm, VAd & $6.01 \pm 0.39$ & $20.97 \pm 4.42$ & $23.68 \pm 7.43$ \\
\hline 9 & $\mathrm{CH}$ & $131.48 \pm 240.47$ & 80 & - & $6.00 \pm 0.38$ & $19.07 \pm 4.99$ & $18.67 \pm 10.49$ \\
\hline 4 & $\mathrm{CH}$ & $123.66 \pm 172.38$ & 100 & VAm, VAd & $5.89 \pm 0.54$ & $18.92 \pm 5.17$ & $19.15 \pm 7.4$ \\
\hline 13 & DR & $94.83 \pm 118.4$ & 97 & VAm, VAd & $6.03 \pm 0.28$ & $18.46 \pm 5.6$ & $28.92 \pm 11.87$ \\
\hline 1 & SW & $74.29 \pm 108.13$ & 100 & - & $6.38 \pm 0.67$ & $17.36 \pm 9.66$ & $9.66 \pm 2.95$ \\
\hline 7 & $\mathrm{CH}$ & $73.46 \pm 139.07$ & 100 & VAm, VAd & $6.02 \pm 0.41$ & $18.57 \pm 4.75$ & $19.96 \pm 5.24$ \\
\hline 5 & $\mathrm{CH}$ & $58.14 \pm 112.5$ & 100 & VAm & $6.01 \pm 0.5$ & $18.22 \pm 5.42$ & $16.73 \pm 6.25$ \\
\hline 12 & $\mathrm{CH}$ & $21.67 \pm 39.79$ & 76 & - & $5.96 \pm 0.12$ & $22.2 \pm 4.53$ & $11.21 \pm 3.96$ \\
\hline 15 & SW & $14.18 \pm 24.37$ & 46 & - & $6.44 \pm 0.51$ & $20.15 \pm 3.12$ & $7.31 \pm 1.65$ \\
\hline 11 & $\mathrm{CH}$ & $9.58 \pm 29.23$ & 73 & - & $6.00 \pm 0.34$ & $19.24 \pm 5.62$ & $18.85 \pm 13.4$ \\
\hline 6 & $\mathrm{CH}$ & $2.98 \pm 5.92$ & 65 & - & $5.82 \pm 0.35$ & $19.39 \pm 4.24$ & $13.55 \pm 6.19$ \\
\hline 14 & $\mathrm{CH}$ & $1.09 \pm 3.02$ & 73 & VAm, VAd & $6.05 \pm 0.49$ & $19.53 \pm 4.47$ & $12.66 \pm 6.98$ \\
\hline 3 & $\mathrm{RP}$ & $0.74 \pm 1.75$ & 46 & VAm & $6.23 \pm 0.27$ & $17.83 \pm 5.58$ & $8.39 \pm 3.59$ \\
\hline 8 & SW & $0.11 \pm 0.27$ & 41 & - & $6.46 \pm 0.4$ & $14.95 \pm 4.69$ & $7.08 \pm 3.83$ \\
\hline 10 & $\mathrm{CH}$ & $0.04 \pm 0.15$ & 62 & - & $5.59 \pm 0.64$ & $17.88 \pm 5.19$ & $17.24 \pm 7.43$ \\
\hline
\end{tabular}

$a$ : sites are listed in decreasing order of mosquito density; $b$ : percentage of sampling dates that each larval habitat contained water; CH: canals; DR: drains; RP: retention ponds; SW: shallow wells; VAm VAd: presence of monocotyledonous or dicotyledonous aquatic emergent vegetation. 
sity. Similar results have been obtained in other localities in Córdoba Province, where the observed $\mathrm{pH}$ ranges were wider (from 6.4-8) and no relationship between this variable and $C x$. quinquefasciatus larval abundance was observed (Almirón \& Brewer 1996). However, in Chaco Province, the presence of immature $C x$. quinquefasciatus stages was positively associated with $\mathrm{pH}$ values ranging from 6.8-8.5 (Stein et al. 2011).

The presence of immature mosquito stages has been recorded at a wide range of breeding sites, from small and highly ephemeral to the large and permanent water bodies (Forattini 2002). Pires and Gleiser (2010) observed that the presence of $C x$. quinquefasciatus larvae in Córdoba city was related to temporary and semi-permanent

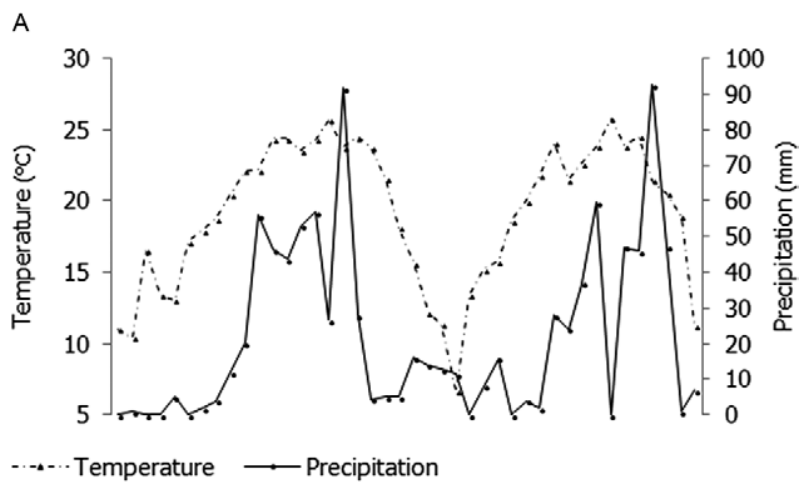

B

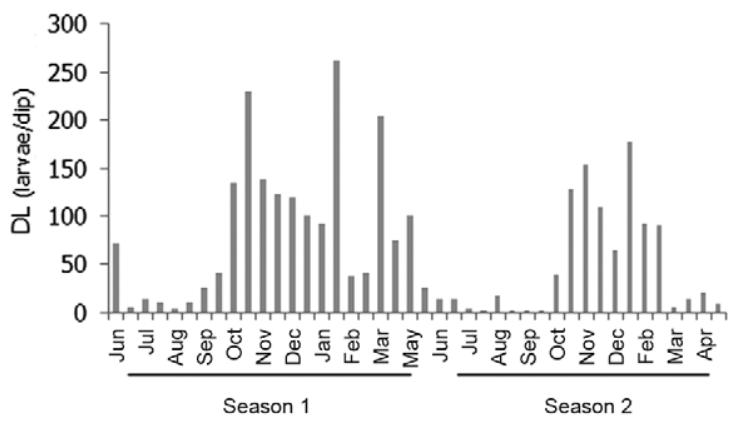

n $\mathrm{DL} C \mathrm{x}$. quinquefasciatus

Fig. 2A, B: mean values of meteorological variables and mosquito density during the study period (June 2008-May 2010). DL: larval density.

TABLE II

Variables from generalised linear mixed models explaining variation in Culex quinquefasciatus larval density with $\mathrm{p} \leq 0.05$ and parameter estimates \pm standard error (SE)

\begin{tabular}{lccc}
\hline Variable & Parameter estimate $\pm \mathrm{SE}$ & $\mathrm{z}$ & $\mathrm{p}$ \\
\hline $\mathrm{T}_{15}$ & $0.16 \pm 0.06$ & 2.54 & 0.011 \\
$\mathrm{VAd}$ & $1.4 \pm 0.58$ & 2.47 & 0.014 \\
\hline
\end{tabular}

$\mathrm{T}_{15}$ : average air temperature 15 days prior to each sampling date; VAd: dicotyledonous aquatic emergent vegetation. water bodies, both of which were associated with rainfall as the water source. However, in this study, breeding sites with high water permanence values (80-100\%) were found to support high $C x$. quinquefasciatus larval densities. Because the eggs of this mosquito cannot tolerate desiccation and hatching occurs when embryonic development is complete (Forattini 2002), permanent breeding sites might be more appropriate than temporary water bodies for immature-stage development.

In this study, the presence of $C x$. quinquefasciatus larvae observed during the entire study period, even during the winter months, with a peak larval density being recorded in February, suggests that the extreme temperatures that occur in Córdoba city (temperate climate) do not prevent larval development. The results of the present work correspond to other surveys of this species in Córdoba city, where $C x$. quinquefasciatus adults and immature stages were collected during all seasons of the year and showed two peaks of larval abundance, in the spring and summer months (Almirón \& Brewer 1995). In Buenos Aires Province (temperate climate), the presence of $C x$. quinquefasciatus has also been reported throughout the year (Fischer et al. 2000, Fischer \& Schweigmann 2010) and immature stages of this species are generally most abundant in the summer (Fischer \& Schweigmann 2004). In subtropical Chaco Province, $C x$. quinquefasciatus, together with Aedes aegypti, has been reported as the most abundant species in artificial larval habitats during the rainy and warm seasons; however, during dry and cold months, the $C x$. quinquefasciatus larval abundance decreases in a manner consistent with the patterns observed in other temperate areas (Stein et al. 2002b). In the present study, the decreased larval density observed during the summer months of the second period could be a consequence of environmental sanitation measures (vegetation removal and larvicide application) applied during January and February 2009 to reduce mosquito larval habitats with the support of the local authorities (no available data). Other factors that were not examined in this study, such as the presence of competitors or predators, might also affect larval abundance.

More recent approaches to disease prevention and vector control programs have focused on the cost-effective utilisation of limited resources to reduce the vector populations (OPS 1995, Knight et al. 2003). Thus, in Córdoba city and perhaps in other localities at the same latitude and with the same environmental conditions, mosquito control programs should focus on permanent larval habitats with aquatic vegetation during the early spring, when the $C x$. quinquefasciatus population begins to increase. Furthermore, the average air temperature during the 15 days prior to collection could be used to develop predictive abundance models for this mosquito species.

\section{ACKNOWLEDGEMENTS}

To the reviewers, for their valuable comments and suggestions to improve the paper.

\section{REFERENCES}

Almirón WR, Brewer ME 1995. Distribución estacional de Culicidae (Diptera) en áreas periféricas de Córdoba (Argentina). Ecol Austral 5: 81-86. 
Almirón WR, Brewer ME 1996. Classification of immature stage habitats of Culicidae (Diptera) collected in Córdoba, Argentina. Mem Inst Oswaldo Cruz 91: 1-9.

Almirón WR, Díaz A, Spinsanti L, Ré V, Visintín A, Farías A, Contigiani MS 2006. Culex pipiens quinquefasciatus y su relación con la encefalitis de San Luis en Córdoba, Argentina. Rev Argent Zoonosis 3: 24-27.

Clements AN 1992. The biology of mosquitoes. Development, nutrition and reproduction, Vol. I, Chapman \& Hall, London, 509 pp.

Crawley MJ 2007. The $R$ book, Wiley \& Sons Ltd/Imperial College London at Silwood Park, Chichester, 877 pp.

Darsie Jr RF 1985. The mosquitoes of Argentina: part I. Keys for identification of adult females and fourth stage larvae in English and Spanish (Diptera: Culicidae). Mosq Syst 17: 153-253.

Díaz LA, Ré V, Almirón WR, Farías A, Vázquez A, Sanchez-Seco MP, Aguilar J, Spinsanti L, Konigheim B, Visintin A, García J, Morales MA, Tenario A, Contigiani M 2006. Genotype III Saint Louis encephalitis virus outbreak, Argentina, 2005. Emerg Infect Dis 12: 1752-1754.

Fischer S, Marinone MC, Fontanarrosa MS, Nieves M, Schweigmann N 2000. Urban rain pools: seasonal dynamics and entomofauna in a park of Buenos Aires. Hydrobiologia 441: 45-53.

Fischer S, Schweigmann N 2004. Culex mosquitoes in temporary urban rain pools: seasonal dynamics and relation to environmental variables. J Vector Ecol 29: 365-373.

Fischer S, Schweigmann N 2010. Seasonal occurrence of immature mosquitoes in swimming pools in Buenos Aires, Argentina. $J \mathrm{Am}$ Mosq Control Assoc 26: 95-98.

Forattini OP 2002. Culicidologia médica. Identificação, biologia, epidemiologia, Vol. II, EDUSP, São Paulo, 864 pp.

INDEC - Instituto Nacional de Estadística y Censos 2010. Censo Nacional de Población, Hogares y Viviendas 2010. Available from: censo2010.indec.gov.ar/preliminares/cuadro_cordoba.asp.

Jarsún B, Gorgas JA, Zamora E, Bosnero E, Lovera E, Ravelo A, Tassile JL 2003. Caracterización general de la provincia. In JA Gorjas, JL Tassile (eds.), Recursos naturales de la provincia de Córdoba, Los Suelos, Agencia Córdoba Ambiente/INTA, Córdoba, p. 23-60.

Knight RL, Walton WE, O'Meara GF, Reisen WK, Wass R 2003. Strategies for effective mosquito control in constructed treatment wetlands. Ecol Eng 21: 211-232.

Lindblade KA, Walker ED, Onapa AW, Katungu J, Wilson ML 2000. Land-use change alters malaria transmission parameters by mod- ifying temperature in a highland area of Uganda. Trop Med Int Health 5: 263-274.

OPS - Organización Panamericana de la Salud 1995. Dengue y dengue hemorrágico en las Américas: guías para su prevención y control, OPS, Washington DC, $110 \mathrm{pp}$.

OPS - Organización Panamericana de la Salud 2010. Alerta epidemiológica: nuevos casos de encefalitis de San Luis en ciudad y provincia de Buenos Aires, República Argentina, riesgo de diseminación. Available from: 2.paho.org/hq/dmdocuments/2010/ alert_epi_2010_31_marz_encefalitis_san_luis.pd.

Pires DA, Gleiser RM 2010. Mosquito fauna inhabiting water bodies in the urban environment of Córdoba city, Argentina, following a St. Louis encephalitis outbreak. J Vector Ecol 35: 401-409.

R Core Team 2012. R: a language and environment for statistical computing. Available from: R-project.org.

Russell RC 1999. Constructed wetlands and mosquitoes: health hazards and management options-an Australian perspective. Ecol Eng 12: 107-124.

SMN - Servicio Meteorológico Nacional 2011. Climatología. Datos estadísticos-turismo. Available from: smn.gov.ar $/$ ?mod=clima\&i $\mathrm{d}=30$ \& provincia $=\mathrm{C} \% \mathrm{~F} 3$ rdoba\& ciudad $=\mathrm{C} \% \mathrm{~F} 3$ rdoba .

Spinsanti L, Díaz LA, Glatstein N, Arselán S, Morales MA, Farías A, Fabbri C, Aguilar J, Ré V, Frías M, Almirón W, Hunsperger E, Siirin M, Travassos da Rosa A, Tesh R, Enría D, Contigiani M 2008. Human outbreak of St. Louis encephalitis detected in Argentina, 2005. J Clin Virol 42: 27-33.

Stein M, Almirón WR, Willener JA, Gorodner JO 2005. Criaderos de estados inmaduros de mosquitos (Diptera: Culicidae) colectados en la provincia del Chaco. Comunicaciones científicas y tecnológicas. Available from: unne.edu.ar/Web/cyt/com2005/6Biologia/B-010.pdf.

Stein M, Gómez MV, Alonso JM 2002a. Culicidos (Diptera) colectados en cuerpos de agua transitorios de la ciudad de Resistencia. Comunicaciones Científicas y Tecnológicas. Available from: 1.unne.edu.ar/cyt/2001/3-Medicas/M-038.pdf.

Stein M, Ludueña-Almeida F, Willener JA, Almirón WR 2011. Classification of immature mosquito species according to characteristics of the larval habitat in the subtropical province of Chaco, Argentina. Mem Inst Oswaldo Cruz 106: 400-407.

Stein M, Oria GI, Almirón WR 2002b. Principales criaderos para Aedes aegypti y culícidos asociados, Argentina. Rev Saude Publica 36: $627-630$

Zuur AF, Ieno EN, Walker N, Saveliev AA, Smith GM 2009. Mixed effects models and extensions in ecology with $R$, Springer, New York, $574 \mathrm{pp}$. 